\title{
UN NUEVO ACUERDO REGIONAL PARA AMÉRICA LATINA Y EL CARIBE SOBRE EL PRINCIPIO 10 DE RÍO - ACUERDO DE ESCAZÚ
}

\author{
A NEW REGIONAL AGREEMENT FOR \\ LATIN AMERICA AND THE CARIBBEAN ON \\ RIVER PRINCIPLE 10 - ESCAZÚ AGREEMENT
}

César A. Ipenza Peralta*

Abogado por la Universidad de San Martín de Porres, Máster en Conservación de espacios naturales protegidos por la Universidad Autónoma de Madrid. Maestría en Gestión Pública por la Universidad de San Martín de Porres. Docente en diversas universidades privadas y públicas. Consultor en asuntos minero ambientales. Expositor en conferencias especializadas minero ambientales. Autor de libros de Derecho Minero y Ambiental.

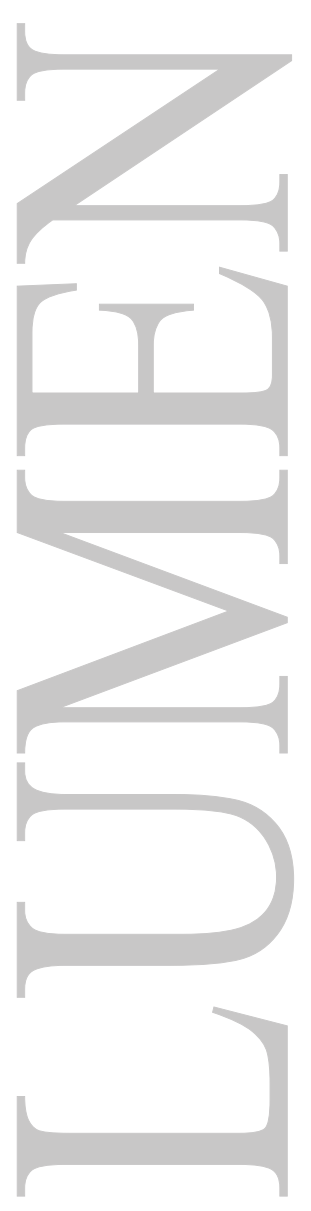




\title{
UN NUEVO ACUERDO REGIONAL PARA AMÉRICA LATINA Y EL CARIBE SOBRE EL PRINCIPIO 10 DE RÍO - ACUERDO DE ESCAZÚ
}

\author{
A NEW REGIONAL AGREEMENT FOR LATIN AMERICA AND THE CARIBBEAN ON RIVER \\ PRINCIPLE 10 - ESCAZÚ AGREEMENT
}

César A. Ipenza Peralta

\begin{abstract}
RESUMEN:
En el presente artículo se aborda el tema del proceso de suscripción y posterior ratificación del Acuerdo Regional sobre el Acceso a la Información, la Participación Pública y el Acceso a la Justicia en Asuntos Ambientales en América Latina y el Caribe o Acuerdo de Escazú. Es un instrumento internacional, para prevenir los conflictos socioambientales porque permite incrementar las medidas tendientes a acceder a la información y generar mecanismos que garanticen una nueva forma de mejorar la toma de decisiones en los Estados.
\end{abstract}

\section{PALABRAS CLAVE:}

Acuerdo Regional sobre el Acceso a la Información, la Participación Pública; Acceso a la Justicia en Asuntos Ambientales en América Latina y el Caribe o Acuerdo de Escazú; Conflictos socio ambientales

\begin{abstract}
:
This article deals with the process of subscription and subsequent ratification of the Regional Agreement on Access to Information, Public Participation and Access to Justice in Environmental Matters in Latin America and the Caribbean or the Escazú Agreement. It is an international instrument to prevent socio-environmental conflicts because it allows increasing the measures aimed at accessing information and generating mechanisms that guarantee a new way of improving decision-making in the States.
\end{abstract}

\section{KEY WORDS:}

Regional Agreement on Access to Information, Public Participation; Access to Justice in Environmental Matters in Latin America and the Caribbean or the Escazú Agreement; Socio-environmental conflicts

\section{INTRODUCCIÓN:}

Si bien la Declaración de Río sobre el Medio Ambiente y el Desarrollo plantea diversos elementos, 27 principios fundamentales para el desarrollo sostenible y las obligaciones de los Estados en materia de ambiental, está ratificó los principios establecidos en la Declaración de la Conferencia de las Naciones Unidas sobre el Medio Humano, aprobada en Estocolmo el 16 de junio de 1972. Estos 27 principios adoptados en este instrumento jurídico no vinculante, forman parte de nuestro sistema jurídico, sin embargo, tiene aún mucho camino por recorrer y por consolidar en nuestra región.

Uno de esos principios, el Principio 10, hoy convertido en el Acuerdo de Escazú o Acuerdo Regional sobre el Acceso a la Información, la Participación Pública y el Acceso a la Justicia en Asuntos Ambientales en América Latina y el Caribe, en adelante Acuerdo, es la implementación concreta y avanzada del principio 10 de Río que señala:

"El mejor modo de tratar las cuestiones ambientales es con la participación de todos Los ciudadanos interesados, en el nivel que corresponda. 
En el plano nacional, toda persona deberá tener acceso adecuado a la información sobre el medio ambiente de que dispongan Las autoridades públicas, incluida La información sobre los materiales y las actividades que encierran peligro en sus comunidades, así como la oportunidad de participar en Los procesos de adopción de decisiones.

Los Estados deberán facilitar y fomentar la sensibilización y la participación de la población poniendo la información a disposición de todos.

Deberá proporcionarse acceso efectivo a los procedimientos judiciales y administrativos, entre estos el resarcimiento de daños y los recursos pertinentes"

El Principio 10, nos lleva a hablar de democracia ambiental, nos evidencia la necesidad de abordar elementos fundamentales para la mejora de la gestión ambiental integral, como la necesidad de contar con información adecuada y oportuna, que nos lleve a la participación plena de todos los actores y a su vez permita acceder a mecanismos adecuados de justicia ambiental, en toda su amplitud y en todos sus enfoques.

Para fines prácticos, entendemos por "Democracia Ambiental" a la necesidad de la participación activa para la toma de decisiones en materia ambiental. Para garantizar este derecho se debe promover el acceso a la información. Reconociendo de manera primigenia el derecho a un ambiente sano y ecológicamente equilibrado, el ciudadano debe tener acceso a la justicia ambiental en sus diversos enfoques que pueden ser: judiciales (penales o civiles), administrativos y constitucionales.

Es pertinente señalar asimismo que el mismo proceso y la aprobación del texto final puede resumirse como un proceso, que ha tenido peculiaridades y elementos importantes a considerar y evidencia una nueva forma de abordar la temática ambiental, donde el público ha tenido voz en una negociación entre los Estados, situación inédita y sin precedentes, pero importante para la forma de cómo se construyen nuevos mecanismos de democracia y de participación en la toma de decisiones.

De conformidad con ello, el objetivo del Acuerdo, se traduce en garantizar la implementación plena y efectiva en nuestra región (América Latina y el Caribe) de los derechos de acceso a la información ambiental, participación pública en los procesos de toma de decisiones ambientales y acceso a la justicia en asuntos ambientales, así como la creación y el fortalecimiento de las capacidades y la cooperación, contribuyendo a la protección del derecho de cada persona, de las generaciones presentes y futuras, a vivir en un medio ambiente sano y al desarrollo sostenible.

Este objetivo, ambicioso también plantea no sólo retos actuales sino también significa una base para sobre ello construir una democracia ambiental, necesaria en una región con altísima no solo riqueza o diversidad natural, sino también cultural, y además conflictividad por el uso de los recursos, y que demanda nuevas formas de administrar nuestros recursos y nuestro patrimonio, y que a su vez demanda Estados más abiertos y democráticos, y repensar en el rol de las instituciones y de los actores sociales diversos, que permitan obtener el máximo beneficio de la colectividad, usando de manera responsable nuestros recursos, y garantizando el pleno derecho a la vida, y a gozar un ambiente sano y equilibrado. Que se traduce a nuestro modelo de desarrollo sostenible, que establece igualdad de condiciones en materia económica, social y ambiental.

\section{Elementos centrales del Acuerdo: Información, Participación y Justicia Ambiental.}

Si uno hace un análisis integral sobre el texto del acuerdo aprobado, puede evidenciarse que gran parte de los instrumentos y elementos planteados y de sus mandatos, son y han sido parte de los elementos que rigen las prácticas de los Estados y del nuestro, sin embargo, esto nos lleva a mejorar y consolidar lo avanzado y a su vez nivelar a nivel regional las reglas para una mejora en la gobernanza ambiental en toda América Latina y el Caribe. 
De acuerdo con el texto del Acuerdo, los Estados deberán garantizar el derecho a acceder a justicia ambiental en procedimientos administrativos y judiciales, así como no solo contar con órganos competentes judiciales y/o administrativos, sino que requieren den conocimientos en materia ambiental, siendo el tema ambiental altamente especializado, asimismo establecer procedimientos sujetos a principios de efectividad, publicidad, transparencia e imparcialidad y además mecanismos de comunicación y difusión de criterios y decisiones judiciales y/o administrativas.

\section{1.- Acceso a la información ambiental}

Para el Acuerdo, se entiende por información ambiental a cualquier información escrita, visual, sonora, electrónica o registrada en cualquier otro formato, relativa al ambiente y sus elementos o componentes y a los recursos naturales, incluyendo aquella que esté relacionada con los riesgos ambientales y los posibles impactos adversos asociados que afecten o puedan afectarlos y la salud, así como la relacionada con la protección y la gestión ambiental.

El artículo 5 de aborda todo lo relacionado a la accesibilidad de la información ambiental, mediante la cual se señala que los países deben garantizar el derecho que permita acceder a la información ambiental "que está en su poder, bajo su control o custodia".

Se señala qué es lo que comprende el derecho de acceso, por ejemplo: solicitar y recibir información sin necesidad de justificar las razones; ser informado si la información solicitada obra o no en poder de la autoridad competente, entre otros, y se señala las situaciones de vulnerabilidad de quien solicita ese acceso, para lo cual deberá establecer procedimientos de atención reciban asistencia para formular sus peticiones y obtener respuesta, dentro de esta situación de vulnerabilidad se incluye a los pueblos indígenas.

Asimismo, ante la denegación del acceso a la información ambiental por estar en el régimen de excepciones establecido en la legislación nacional, se deberá comunicar por escrito, incluyendo las disposiciones jurídicas y las razones que en cada caso justifiquen esta decisión, e informar al solicitante de su derecho de impugnarla y recurrirla.

Este artículo 5, plantea las condiciones aplicables para la entrega de información ambiental, para lo cuál se debe garantizar que se entregue en el formato requerido por el solicitante siempre que esté disponible y responder a una solicitud de información ambiental con la máxima celeridad posible, en un plazo no superior a 30 días hábiles contados a partir de la fecha de recepción de la misma, o en un plazo menor si así lo previera expresamente la normativa interna.

Y si no se poseyera la información requerida, debe comunicarlo al solicitante con la máxima celeridad posible, incluyendo, en caso de poderlo determinar, la autoridad que pudiera tener dicha información, además la información ambiental deberá entregarse sin costo, siempre y cuando no se requiera su reproducción o envío. Los costos de reproducción y envío deberán ser razonables y darse a conocer por anticipado.

Con este primer elemento, la información se entiende que se garantiza los siguientes elementos del Acuerdo, como son la participación efectiva y finalmente la justicia ambiental.

\subsection{Mecanismos de revisión independientes}

El Acuerdo enuncia que se debe establecer o designar uno o más órganos o instituciones imparciales y con autonomía e independencia, con el objeto de promover la transparencia en el acceso a la información ambiental, fiscalizar el cumplimiento de las normas, así como vigilar, evaluar y garantizar el derecho de acceso a la información. Asimismo, se podrá incluir o fortalecer, según corresponda, 
las potestades sancionatorias de dichos órganos. Este mecanismo debe llevar a nuestros Estados y al Perú a plantear formas ingeniosas sin la necesidad de la creación de nuevos espacios de gobierno o autoridades.

Finalmente es importante en este contexto, recordar la Sentencia del Tribunal Constitucional, de fecha 6 de abril del 2004, expediente $N^{\circ}$ 2579-2003-HD, caso Julia Eleyza Arellano Serquén donde se ha manifestado de la siguiente manera: "Lo realmente trascendental, a efectos de que pueda considerarse como "información pública", no es su financiación, sino la posesión y el uso que le imponen los órganos públicos en la adopción de decisiones administrativas, salvo, claro está que la información haya sido declarada por ley y como sujeta a reserva."

\section{2.- Participación pública en los procesos de toma de decisiones ambientales}

El artículo 7 del Acuerdo, señala que los países deben asegurar el derecho de participación, para ello deben implementar una participación abierta e inclusiva en los procesos de toma de decisiones ambientales, así como en revisiones, reexaminaciones o actualizaciones relativos a proyectos y actividades, así como en otros procesos de autorizaciones ambientales que tengan o puedan tener un impacto significativo sobre el medio ambiente, incluyendo cuando puedan afectar la salud.

Para lo cual, se señala que esta participación se deberá dar desde etapas iniciales del proceso de toma de decisiones, de manera que las observaciones que pudieran existir sean debidamente consideradas, además se deberá proporcionará de manera clara, oportuna y comprensible, la información necesaria para hacer efectivo el derecho a participar en el proceso de toma de decisiones.

Este artículo señala que los Estados deberán informar de forma efectiva, comprensible y oportuna, a través de medios apropiados, que pueden incluir los medios escritos, electrónicos u orales, así como los métodos tradicionales, como mínimo sobre:

- El tipo o naturaleza de la decisión ambiental de que se trate de forma sencilla.

- La autoridad responsable del proceso de toma de decisiones y otras autoridades e instituciones involucradas.

- El procedimiento previsto para la participación, los mecanismos previstos para dicha participación, y, cuando corresponda, los lugares y fechas de consulta o audiencia pública; y

- Las autoridades públicas involucradas a las que se les pueda requerir mayor información sobre la decisión ambiental de que se trate-

Establece además que la ciudadanía o público, podrán presentar observaciones por medios apropiados y disponibles, conforme a las circunstancias del proceso. Antes de la adopción de la decisión, la autoridad pública que corresponda tomará debidamente en cuenta el resultado del proceso de participación.

Este instrumento internacional, establece que la difusión de las decisiones que resultan de las evaluaciones de impacto ambiental y de otros procesos de toma de decisiones ambientales que involucran la participación pública deberá realizarse a través de medios apropiados, que podrán incluir los medios escritos, electrónicos u orales, así como los métodos tradicionales, de forma efectiva y rápida. La información difundida deberá incluir el procedimiento previsto que permita al público ejercer las acciones administrativas y judiciales pertinentes. 
Se debe contar con las condiciones propicias para que la participación pública en procesos de toma de decisiones ambientales se adecúe a las características sociales, económicas, culturales, geográficas y de género del público y además considerar el idioma.

El texto del acuerdo señala que se hará pública al menos la siguiente información antes de la toma de decisión:

- La descripción del área de influencia y de las características físicas y técnicas del proyecto o actividad propuesto,

- La descripción de los impactos ambientales del proyecto o actividad y, según corresponda, el impacto ambiental acumulativo;

- La descripción de las medidas previstas con relación a dichos impactos;

- un resumen de los puntos anteriores en lenguaje no técnico y comprensible;

- Los informes y dictámenes públicos de los organismos involucrados dirigidos a la autoridad pública vinculados al proyecto o actividad de que se trate;

- La descripción de las tecnologías disponibles para ser utilizadas y de los lugares alternativos para realizar el proyecto o actividad sujeto a las evaluaciones, cuando la información esté disponible; y

- Las acciones de monitoreo de la implementación y de los resultados de las medidas del estudio de impacto ambiental.

Estos elementos anteriormente considerados están en gran medida recogidos en nuestra Ley del Sistema Nacional de Evaluación de Impacto ambiental y también en la práctica de las autoridades sectoriales y de evaluación ambiental.

La participación en materia ambiental implica que los ciudadanos y población sean informados y puedan participar en la toma de decisiones sobre los asuntos que afectan o puedan afectar su calidad de vida. Estas decisiones gubernamentales incluyen aquellas que pueden influir en la calidad del aire que respiran, la calidad del agua que toman y la calidad de los recursos naturales de los que dependen. Por tanto, una participación activa y consciente de los ciudadanos garantiza la toma de mejores decisiones públicas que inciden sobre el ambiente.

Es pertinente en este contexto recordar el Artículo $2^{\circ}$ numeral 22 de nuestra Constitución Política que establece que toda persona tiene derecho a gozar de un ambiente equilibrado y adecuado al desarrollo de su vida. Asimismo, el Artículo I del Título Preliminar de la Ley N²8611, Ley General del Ambiente (LGA), que precisa que las personas no solo tienen el derecho irrenunciable a vivir en un ambiente saludable, equilibrado y adecuado para el pleno desarrollo de la vida; sino, además, el deber de contribuir a una efectiva gestión ambiental y de proteger el ambiente. Si bien nuestra Constitución ha reconocido al ambiente como un bien o interés colectivo, configurando el disfrute de un ambiente adecuado como un derecho de la comunidad en su conjunto. La realización de este derecho no solo recae en los poderes públicos sino también en todos los integrantes de la comunidad, que tienen, como expresamente señala la LGA, "el deber" de proteger el medio ambiente

Es por ello que la Constitución contempla el goce de un medio ambiente sano y equilibrado como un derecho colectivo y, mediante ley, se ha garantizado la participación de la comunidad en las decisiones que puedan afectar dicho bien jurídico. En este contexto, se ha establecido que los ciudadanos tienen el derecho - deber de participar en el proceso de toma de decisiones públicas sobre materia ambiental. Su participación garantiza la toma de mejores decisiones públicas y, con ello, una efectiva protección o conservación del medio ambiente. 


\section{3.- Acceso a la justicia en asuntos ambientales}

En el artículo 8 se especifica que los países deben garantizar el derecho a acceder a la justicia en asuntos ambientales de acuerdo con las garantías del debido proceso, para lo cual se debe asegurar, en el marco de la legislación nacional, el acceso a instancias judiciales y administrativas para impugnar y recurrir, en cuanto al fondo y el procedimiento:

- Cualquier decisión, acción u omisión relacionada con el acceso a la información ambiental,

- Cualquier decisión, acción u omisión relacionada con la participación pública en procesos de toma de decisiones ambientales, y

- Cualquier otra decisión, acción u omisión que afecte o pueda afectar de manera adversa al medio ambiente o contravenir normas jurídicas relacionadas con el medio ambiente.

\subsection{Mecanismos para garantizar el derecho de acceso a la justicia en asuntos ambientales:}

- Órganos estatales competentes con acceso a conocimientos especializados en materia ambiental;

- Procedimientos efectivos, oportunos, públicos, transparentes, imparciales y sin costos prohibitivos;

- Legitimación activa amplia en defensa del medio ambiente, de conformidad con la legislación nacional;

- La posibilidad de disponer medidas cautelares y provisionales para, entre otros fines, prevenir, hacer cesar, mitigar o recomponer daños al medio ambiente;

- Medidas para facilitar la producción de la prueba del daño ambiental, cuando corresponda y sea aplicable, como la inversión de la carga de la prueba y la carga dinámica de la prueba;

- Mecanismos de ejecución y de cumplimiento oportunos de las decisiones judiciales y administrativas que correspondan; y

- Mecanismos de reparación, según corresponda, tales como la restitución al estado previo al daño, la restauración, la compensación o el pago de una sanción económica, la satisfacción, las garantías de no repetición, la atención a las personas afectadas y los instrumentos financieros para apoyar la reparación.

El Acuerdo señala que, para facilitar el acceso a la justicia en asuntos ambientales, se establecerá:

- Medidas para reducir o eliminar barreras al ejercicio del derecho de acceso a la justicia,

- Medios de divulgación del derecho de acceso a la justicia y los procedimientos para hacerlo efectivo,

- Mecanismos de sistematización y difusión de las decisiones judiciales y administrativas que correspondan, y

- El uso de la interpretación o la traducción de idiomas distintos a los oficiales cuando sea necesario para el ejercicio de ese derecho.

También se señala que las decisiones judiciales y administrativas adoptadas en asuntos ambientales, así como su fundamentación, estén consignadas por escrito, y promover mecanismos alternativos de solución de controversias en asuntos ambientales, en los casos en que proceda, tales como la mediación, la conciliación y otros que permitan prevenir o solucionar dichas controversias.

\subsection{La Justicia Ambiental en el Perú:}

Para hablar de justicia ambiental, debemos recordar la amplitud de la misma, y que trasciende los procesos judiciales (penal y civil), administrativos y constitucionales y permite sobre todo ejercer nuestro derecho a gozar de un ambiente sano y equilibrado. 
Este tema no está aislado del desarrollo en los que el Perú está inmerso, como por ejemplo se alinean al proceso para implementar las recomendaciones formuladas por la OCDE a nuestro país, en el marco de la Evaluación del Desempeño Ambiental. Ello implica, entre otros temas, "mejorar las capacidades del Poder Judicial, el Ministerio Público y demás entidades del sistema de justicia con responsabilidad en la aplicación de la ley para atender temas ambientales, la creación de tribunales especializados, ampliando los mecanismos de formación, así como mejorar las capacidades de soporte técnico y científico para las labores de administración de justicia".

Además, los diversos Poderes del Estado, liderados por el Poder Judicial a través de su Comisión Nacional de Gestión, se viene impulsando la iniciativa denominada "Pacto de Madre de Dios por la Justicia Ambiental", este compromiso llevará a muchos sectores y Poderes del Estado a mejorar las condiciones para implementar los mecanismos existentes de protección de los derechos humanos, de la vida, de la salud y del gozar de un ambiente sano y equilibrado. Derechos reconocidos en nuestra Constitución Política.

Esta iniciativa releva la necesidad de avanzar en implementar mejoras del desempeño de la Justicia Ambiental en el Perú y aplicar compromisos comunes relacionadas al acceso y la aplicación de la Ley frente al creciente número de demandas y reclamaciones que se están registrando en materia administrativa, penal, contenciosa administrativo, constitucional y civil; difundir el alcance e importancia de los principios y derechos ambientales, y de gestión ambiental, acciones que ya se han venido desarrollando a través de actividades de capacitación, más aun cuando la alta especialización de la gestión ambiental lo requiere y no sólo con el Poder Judicial sino también con las Fiscalías Especializadas en Materia Ambiental y con la ciudadanía en general.

\section{4.- Defensores de los derechos humanos en asuntos ambientales: Implicancias para el Perú}

Es importante reconocer o partir de la premisa que, si bien los derechos ambientales están recogidos en más de cien (100) Constituciones, requiere que sean aplicados y también generar mecanismos y garantías para todas las autoridades y ciudadanos que trabajan en favor de cumplir este derecho, sin embargo "entre los años 2002 y 2013, 908 personas murieron defendiendo el medio ambiente y la tierra en 35 países. En 2017 la tendencia empeoró, cuatro defensores del medio ambiente fueron asesinados cada semana, según documentó en enero de 2018 la ONG Global Witness. Entre 40\% y 50\% de los 197 defensores asesinados en 2017 provenían de comunidades indígenas y locales. Muchas más personas fueron hostigadas, intimidadas y obligadas a abandonar sus tierras. Al menos $60 \%$ de los crímenes ocurrieron en América Latina y el Caribe, una región rica en recursos naturales que desde hace años ocupa el primer lugar entre las zonas más peligrosas del mundo para los defensores del medio ambiente".

\section{1.- ¿Quiénes son defensores de derechos humanos en temas ambientales?}

Es pertinente para dar elementos y entender qué es un defensor ambiental, revisar el informe del Sr. Michael Frost, Relator Especial sobre la situación de los defensores de derechos humanos la cual fue respaldada por el Sr. John Knox, Relator Especial de las Naciones Unidas sobre las obligaciones de derechos humanos relacionadas con el disfrute de un medio ambiente seguro, limpio, saludable y sostenible, según la cual los "defensores de los derechos humanos ambientales" son aquellas personas y grupos que, a título personal o profesional, se esfuerzan por proteger y promover los derechos humanos relacionados con el medio ambiente. Según indica el relator, "sus orígenes son diversos y trabajan de diferentes maneras. Algunos son abogados o periodistas, pero muchos son personas comunes que viven en aldeas remotas, bosques o montañas, que tal vez ni siquiera sean conscientes de que están actuando como defensores ambientales en procura del respeto los derechos humanos"

Es así que el artículo 9, del Acuerdo, señala que los países deben generar un entorno seguro y propicio en el que las personas, grupos y organizaciones que promueven y defienden los derechos humanos en asuntos ambientales puedan actuar sin amenazas, restricciones e inseguridad. 
Además de ello, señala, se deberá tomar medidas adecuadas y efectivas para reconocer, proteger y promover todos los derechos de los defensores de los derechos humanos en asuntos ambientales, incluidos su derecho a la vida, integridad personal, libertad de opinión y expresión, derecho de reunión y asociación pacíficas y derecho a circular libremente; además medidas apropiadas, efectivas y oportunas para prevenir, investigar y sancionar ataques, amenazas o intimidaciones que los defensores de los derechos humanos en asuntos ambientales puedan sufrir en el ejercicio de los derechos contemplados en el presente Acuerdo.

\section{2.- Plan Nacional de Derechos Humanos 2017-2021}

Es pertinente señalar que frente a este tema particular, el Estado peruano aprobó el Plan Nacional de Derechos Humanos 2017-2021 mediante el Decreto Supremo N 002-2018-JUS de fecha 31 de enero del 2018, suscrita por todos los Ministros de Estado en cuyo: Lineamiento Estratégico $\mathrm{N}^{\circ}$ 3: Diseño y Ejecución de Políticas a favor de los Grupos de Especial Protección, se consideran a los Defensores de Derechos Humanos, y donde el Estado peruano se compromete a fomentar mecanismos para garantizar el ejercicio seguro de la labor pacífica y no violenta, retribuida o gratuita, de las defensoras y los defensores de derechos humanos en todo el territorio nacional. Para lo cual se han identificado metas y responsabilidades para:

- Generar un Registro de situaciones de riesgo de defensores de Derechos Humanos

- Un mecanismo implementado para la protección de defensoras y defensores de derechos humanos.

Cómo se evidencia con la aprobación del Plan Nacional de Derechos Humanos, el estado peruano ha emprendido medidas previas para garantizar el derecho de los grupos en situación de vulnerabilidad como pueden y son los defensores del medio ambiente.

\section{CONCLUSIONES}

- El proceso de suscripción y posterior ratificación del Acuerdo Regional sobre el Acceso a la Información, la Participación Pública y el Acceso a la Justicia en Asuntos Ambientales en América Latina y el Caribe o Acuerdo de Escazú es un reto, que debe llevar a saber traducir y explicar las implicancias de su texto a los Estados, desde su apertura a la firma en la próxima Asamblea General de las Naciones Unidas el 27 de septiembre 2018.

- Existe un rol indesligable del público y de la sociedad civil en el proceso, quienes no sólo son agentes fundamentales para dar a conocer el Acuerdo de manera pertinente, sino también para dar seguimiento de este proceso hasta después de entrada en vigencia a nivel internacional, una vez ratificada por once (11) de los 33 países de ALC.

- Los tres elementos del acuerdo resultan interdependientes Acceso, Participación y Justicia Ambiental, por lo que requiere una lectura integral, y un avance en igualdad de condiciones en los países, por eso allí radica la importancia que el acuerdo aborde estos tres elementos de manera integral, siendo el acuerdo no el techo, lo máximo, sino la base mínima.

- Acceso a la Justicia no se traduce solo en la existencia de juzgados especializados o fiscalías, sino espacios y autoridades con conocimientos especializados en materia ambiental, que, por la particularidad, complejidad requiere del desarrollo de herramientas procesales. Debemos entender que la materia ambiental es un tema técnico, y como tal requiere todo el respaldo técnico en las decisiones que se tomen, asimismo los delitos ambientales, que son especializados requieren un profundo conocimiento y sensibilidad, la lógica de un delito común no es aplicable a ellos. 
- Este es un Acuerdo de Derechos Humanos, requiere el concurso de todos los sectores y Poderes del Estado. Se evidencia una necesidad de articular entre todas las autoridades y Poderes del Estado para garantizar ese derecho a gozar de un ambiente sano y equilibrado, hemos avanzado, pero requiere seguir sumando actores. Entonces se requiere conocimiento de las competencias por parte de todos los operadores de justicia, para poder acceder a la justicia ambiental de manera oportuna y adecuada.

- Este instrumento internacional, es una herramienta para prevenir los conflictos socioambientales porque permite incrementar las medidas tendientes a acceder a la información y generar mecanismos que garanticen una nueva forma de mejorar la toma de decisiones en los Estados.

- Finalmente, si bien en el Perú ha habido avances importantes en materia de acceso, participación y justicia ambiental, aún no se aplica plenamente y persisten desafíos para garantizar el ejercicio cabal de los derechos de acceso como instrumento eficaz para empoderar a la sociedad.

\section{REFERENCIAS}

- Comisión Económica para América Latina y el Caribe (CEPAL), Acceso a la información, la participación y la justicia en asuntos ambientales en América Latina y el Caribe: hacia el logro de la Agenda 2030 para el Desarrollo Sostenible (LC/TS.2017/83), 2018.

- PNUMA (Programa de las Naciones Unidas para el Medio Ambiente) (2015), Poner en práctica el Principio 10 de Río: una guía de implementación de las Directrices de Bali del PNUMA para la elaboración de legislación nacional sobre el acceso a la información, participación pública y acceso a la justicia en materia de medio ambiente, Nairobi, octubre.

- PNUMA (Programa de las Naciones Unidas para el Medio Ambiente) (2010), Directrices para la elaboración de legislación nacional sobre el acceso a la información, la participación del público y el acceso a la justicia en asuntos ambientales, Nairobi, febrero.

- Orellana, M. (2014), "Democracia ambiental y desarrollo sostenible: hacia un instrumento regional sobre derechos de acceso", Informe Ambiental Anual 2014, Buenos Aires, Fundación Ambiente y Recursos Naturales (FARN). 